\title{
CERN plan to train science entrepreneurs
}

[GENEVA] CERN, the European Laboratory for Particle Physics, is stepping up its technology-transfer activities in response to pressure from its 19 member states.

The Geneva-based laboratory has created a directorship for technology transfer to oversee an expansion of its training programmes for young scientists and engineers and of its patenting activities.

The changes are being implemented by CERN's director-general Luciano Maiani, former president of the Italian particle physics organization INFN, who joined CERN last year. The INFN also has an action plan of its own to promote technology transfer.

CERN has appointed a director of technology transfer, Hans Hoffmann, who will take up the position in June. The laboratory puts 1,000 young scientists each year through its doctoral and postdoctoral training schemes, and Hoffmann estimates that more than half of them move immediately into industry, mainly to take up jobs as information scientists.

The laboratory will now offer these people additional courses in entrepreneurship and intellectual property rights, to encour-

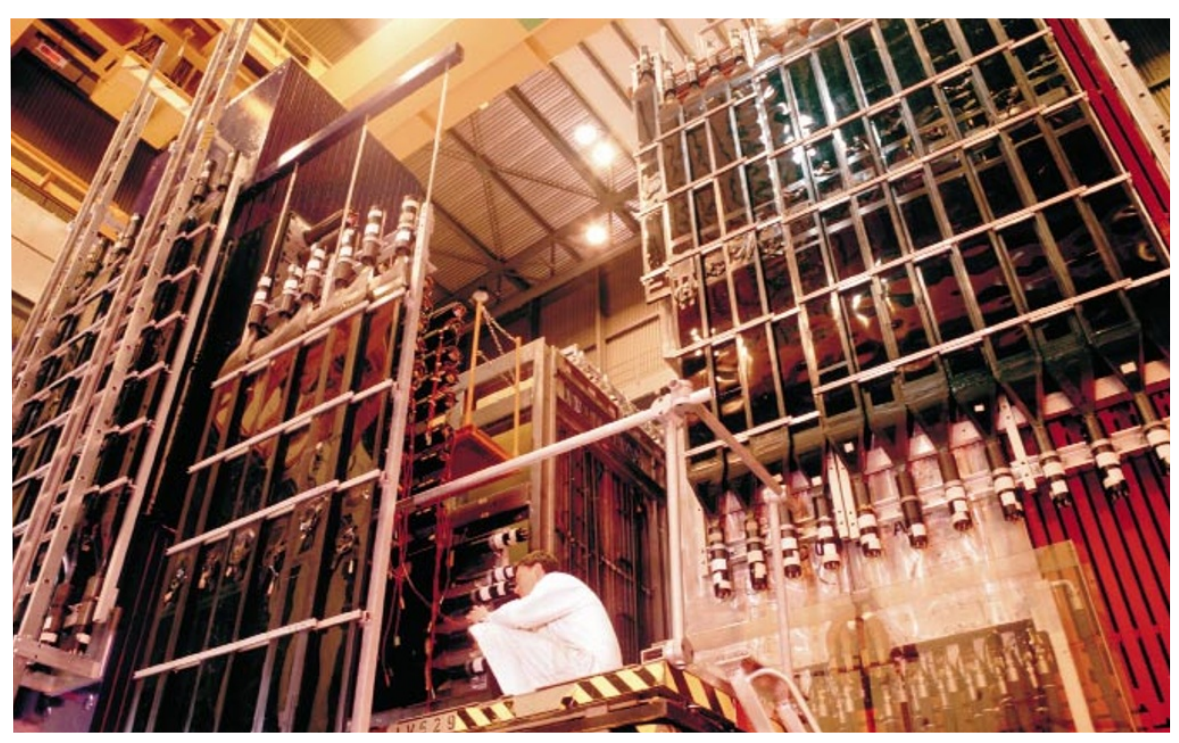

Industrial awareness: CERN training will include business studies and intellectual property rights.

age them to start their own companies when they finish training.

It will also keep a sharper eye out for patentable inventions. CERN has been criticized in the past for failing to profit from important inventions such as the World-

\section{'Don't try to change embryo research law'}

[MUNICH] Now is not the right time to campaign for a relaxation of Germany's tight laws on human embryo research, as some scientists have demanded, according to a policy statement issued last week by the Deutsche Forschungsgemeinschaft (DFG), Germany's basic research funding agency.

Any attempt to reconsider the law could backfire, explains Rüdiger Wolfrum, vicepresident of the DFG, because the public is not fully aware of the medical potential of human embryo research.

The DFG has assessed the existing laws to establish exactly how German researchers are placed to conduct research related to embryos. It finds that they are free to use one particular source of human embryonic stem cells - which are still capable of dividing and developing - for the many different lines of medical research which the DFG considers justified, including the development of cell transplantation therapies for incurable diseases such as Alzheimer's and Parkinson's.

The law does not allow researchers to use embryos developed from spare eggs collected during in vitro fertilization. The Embryo Protection Law confers a human egg with full human rights from the moment of fertilization. Attempts to bypass fertilization by transferring genetic material directly into an enucleated human egg - cloning - are also expressly forbidden.

But there is no legal impediment to scientists isolating primordial germ cells from aborted fetuses and culturing them under conditions that allow them to develop into pluripotent human stem cells, which are committed to developing into one particular sort of body tissue. Under normal conditions, a fertilized egg divides initially into totipotent cells, which have the potential to develop into any sort of tissue, and thus theoretically into a complete human, but they become pluripotent after a few cell divisions.

Scientists have already established that pluripotent stem cells may be generated from fetal material in mice. Studies in the United States indicate that this principle will also apply to human material (see Nature $397,185 ; 1999)$, allowing researchers to bypass the need to handle legally protected totipotent cells. The DFG says it will support studies that further this area of research.

The DFG is aware of the ethical sensitivity of the issue. It calls for the establishment of a central committee to assess the ethical, legal and scientific implications of research proposals involving the use of human embryonic stem cells, and to monitor any projects undertaken. It also calls for a full and open discussion of all these issues at European level.

A. A.
Wide Web, which was developed in 1989 by Tim Berners-Lee during his six-year stay at the laboratory.

The laboratory has filed only a handful of patent applications in its entire history, says Hoffmann. It has operated on the basis that, as a basic research organization, all information and discoveries should be made freely and immediately available. Hoffmann says this will continue to be the case - but that the publication of some information may be delayed until decisions have been made about patent filing.

CERN is also sensitive to concerns of its member states that the licensing of patents should be fairly distributed between them. Some members, including the United Kingdom, have complained that patents taken out by former CERN director general Carlo Rubbia were transferred to a company in Spain, without allowing other countries to put forward any interests of their own. The patents related to technologies involved in Rubbia's so-called energy amplifier, which uses a particle accelerator to drive a subcritical reactor which burns highly radioactive nuclear waste to generate energy.

INFN, meanwhile, hopes to use European Union structural funds - subsidies to poorer regions - to support an industrial training scheme which it plans to launch in the summer.

The scheme, which the organization is currently discussing with industry, would employ large numbers of industrial trainees for short periods in INFN institutes in the south of Italy.

INFN president Enzo Iarocci comments: "We will maintain our identity as a basic research organization, while responding to pressure from industry to 'give something back."'

Alison Abbott 